\title{
The prognostic value of negative lymph node count for patients with cervical cancer after radical surgery
}

\author{
Hao Lu ${ }^{1, *}$, Rong Guo ${ }^{2, *}$, Haotian Yang ${ }^{3,4, *}$, Haolu Wang ${ }^{3}$, Xiaowen Liang ${ }^{3}$, Zhiqian Hu ${ }^{1}$ \\ and Xinxing $\mathbf{L i}^{1}$ \\ ${ }^{1}$ Department of General Surgery, Changzheng Hospital, The Second Military Medical University, Shanghai, China \\ ${ }^{2}$ The First Affiliated Hospital of Gannan Medical University, Ganzhou, Jiangxi, China \\ ${ }^{3}$ Therapeutics Research Centre, The University of Queensland Diamantina Institute, The University of Queensland, \\ Translational Research Institute, Woolloongabba, QLD, Australia \\ ${ }^{4}$ School of Biomedical Sciences, The University of Queensland, St Lucia, QLD, Australia \\ *These authors contributed equally to this work \\ Correspondence to: Xinxing Li, email: xingxin 123456@sina.com \\ Zhiqian Hu, email: huzhiq163@163.com \\ Keywords: negative lymph node; cervical cancer; radical surgery; SEER
}

Received: July 18, $2017 \quad$ Accepted: December 15,2017 Published: December 21, 2017

Copyright: Lu et al. This is an open-access article distributed under the terms of the Creative Commons Attribution License 3.0 (CC BY 3.0), which permits unrestricted use, distribution, and reproduction in any medium, provided the original author and source are credited.

\section{ABSTRACT}

Negative lymph node (NLN) count has been recognized as a prognostic indicator in various cancers. However, the relationship between NLN count and the prognosis of cervical cancer is still unknown. In this study, 10, 500 cervical cancer patients after radical surgery were selected from Epidemiology and End Results Program (SEER) data. Clinicopathological characteristics were collected for analysis, including year of diagnosis, age, race, grade, primary site, FIGO stage and cause specific survival (CSS). Univariate and multivariate Cox proportional hazards model was used to assess risk factors for survival of patients. X-tile plots identified 6 as the optimal cutoff value of NLN count to divide patients into high and low risk subsets in terms of CSS $\left(X^{2}=183.95, P<0.001\right)$. The rate of 5-year CCS of cervical cancer patients was improved with an increase in NLN count from 0 to 23 (all $P<0.001$ ). NLN count was validated as an independently prognostic factor by the multivariate Cox analysis (HR: $1.571,95 \%$ CI: $1.370 \sim 1.801, P<0.001)$. Subgroup analysis showed that NLN count was a prognosis factor in FIGO stage $I\left(X^{2}=35.023, P<0.001\right)$, stage II $\left(X^{2}=12.910\right.$, $P<0.001)$, stage III + IV $\left(X^{2}=9.732, P=0.002\right)$ and unknown stage $\left(X^{2}=16.654\right.$, $P<0.001)$. Conclusively, this study demonstrated the NLN count was an independent prognostic factor for cervical cancer patients.

\section{INTRODUCTION}

Cervical cancer is the fourth most common female malignancy worldwide [1-4]. For women with early-stage disease, radical hysterectomy and pelvic lymphadenectomy are the standard treatments and regional lymph node dissection is important to the survival outcome. Despite the lymph node status does not affect the staging of cervical cancer in the current International Federation of Gynecology and Obstetrics (FIGO) staging system [5], recent studies have revealed that the lymph node status such as lymph node ratio have prognostic value for survival of patients with cervical cancer [6-11]. The node-positive cervical cancer is heterogeneous and the prognosis of these patients cannot be stratified by the definite node-stage. The concept of negative lymph node (NLN) counts has attracted attention recently. NLN count can serve as a prognostic indicator in various cancers, such as colon [12], breast [13], esophagus [14] and gastric [15]. However, the correlation between NLN count and patient prognosis in cervical cancer is not fully studied. This retrospective study investigated the relationship between NLN counts and survival of 
cervical cancer patients who received radical surgery. We used Surveillance Epidemiology and End Results (SEER) database to investigate this association, and determine the optimal cutoff value of NLN counts.

\section{RESULTS}

\section{Demographic and clinicpathological characteristics in SEER database}

In total, we selected 10, 500 eligible patients with M0 cervical cancer who received radical surgery from 2004 to 2012. All patients did not receive neoadjuvant therapy. The median age of patients was 43 years (mean, $44.80 \pm 12.91$ years). The median survival time was 54 months in SEERdata. There were 1, 135 patients with NLN counts ranging from 0 to 6, and 9, 365 patients with NLN counts 7 or more than 7 . These were $69.93 \%(7,343 / 10,500), 9.55 \%$ (1, 003/10, 500), 2.49\% (261/10, 500), 0.30\% (32/10, 500) and $17.72 \%(1,861 / 10,500)$ patients in FIGOI, II, III, IV and unknown stage, respectively. Since minimal cases in FIGO III and IV, we combined data of FIGO III and IV in the subsequent data analysis.

The demographic and tumor characteristics of patients were summarized in Table 1. A total of $31.15 \%$ (3, $271 / 10,500)$ patients received postoperative radiotherapy. The NLN number was correlated with the year of diagnosis, age, race, grade, histologic type, FIGO stage and radiation after surgery (all $P<0.05$ ).

\section{The optimal cutoff points for NLNs determined by $\mathrm{X}$-tile program}

We analyzed the prognostic outcome utilizing various NLN count ranging from 0 to 23 to assess the impact of different NLN count on CSS. The 5-year CSS was calculated for patients with NLNs number or more nodes and less than NLN nodes. Table 2 demonstrated that NLN count was a prognosis factor (all $P<0.001$ ). The 5-year CSS rate increased from $40.8 \%$ to $91.4 \%$.

As shown in Figure 1, X-tile plots were constructed and the maximum $\chi^{2}$ log-rank value of 182.842 (6 as the NLN count, $P<0.001$ ) was produced, applying 6 as the optimal cutoff value to divide the patients into high and low risk subsets in terms of CSS. Compared to patients with NLN count $\leq 6$, patients with NLN count $>6$ showed a significant improvement in 3 and 5-year CSS of $11.30 \%$ and $12.60 \%$, respectively (Table 3 ).

\section{Impact of the number of NLNs on CSS in the patients with cervical cancer}

Univariate analysis revealed that the number of NLNs $(P<0.001)$ and other clinicopathological factors, including age $(P<0.001)$, race $(P=0.002)$, grade $(P<0.001)$, primary site $(P<0.001)$, histologic type
$(P<0.001)$, FIGO stage $(P<0.001)$, and radiation after surgery $(P<0.001)$ were significantly correlated with the prognostic outcome in cervical cancer patients (Table 3). According to the Multivariate Cox regression analysis, survival of cervical patients was improved ( $\mathrm{HR}=1.571$, 95\% CI: $1.370 \sim 1.801, P<0.001)$ with an increase in the number of NLNs, indicating the number of NLNs was an independent predictors of CSS (Table 3).

\section{Impact of the NLN count on CSS in different FIGO stages}

According to the FIGO staging system, patients from SEER-data were divided into 5 subgroups, including stage I, II, III, IV and unknown. Since minimal cases in FIGO III and IV, we combined stage III and IV in one group: FIGO III+IV. We then further analyzed the effects of NLN on survival of each subgroup. We confirmed that the NLN count was an independently prognostic factor in each subgroup using univariate analysis (all $P<0.05$ ) (Figure 2). After adjusting variables, the NLN count was also validated as an independent survival factor in FIGO stage I (NLNs $>6$, HR: 1.685 , 95\% CI: 1.338 2.122; $P<0.001)$, FIGO stage II (NLNs >6, HR: 1.512, 95\% CI: 1.163 1.965; $P=0.002)$, FIGO stage III + IV (NLNs $>6,1.608,95 \%$ CI: $1.154 \sim 2.242 ; P=0.005)$ and unknown stage (NLNs $>6$, HR: $1.438,95 \%$ CI: $1.050 \sim 1.971 ; P=0.024$ ) (Table 4).

\section{DISCUSSION}

Despite the current UICC/AJCC (Union for International Cancer Control /American Joint Committee on Cancer) and FIGO staging system do not consider the status of lymph nodes in cervical cancer, various studies have confirmed that it plays an important role in prognostic survival of patients [16-19]. Zhou et al. concluded that positive LN counts had prognostic value in lymph node positive stage I-II of cervical cancer [6]. However, the lymph node ratio and the number of positive lymph node were affected by many factors such as the number of lymph node retrieved and inspected, and neoadjuvant therapy. If the LN retrieved was not enough, the prediction of survival would be inaccurate. It has been reported that the NLN count was an independent prognosis factor in colon [20,21], gastric [22], esophageal [14] and so on. Although Chen et al. [11] confirmed that the combination of NLNs count and the ratio of positive and removed lymph nodes could better predict the postoperative survival in patients with cervical cancer, the association between NLN counts and survival was not fully explored. In this study, we found that the rate of 5 -year CCS of cervical cancer patients was improved with the increase of NLN count from 0 to 23 (all $P<0.001$ ), and identified the optimal cutoff value for NLN count as 6. Furthermore, the NLN count was an independent prognosis factor for patients with cervical cancer of each 
Table 1: Baseline demographic and tumor characteristics of patients with cervical cancer in SEER database

\begin{tabular}{|c|c|c|c|c|c|c|}
\hline Parameter & Characteristic & $N$ & $N L N=0 \sim 6$ & $\mathbf{N L N}=7 \sim$ & $\chi^{2}$ & $P$ value \\
\hline \multirow[t]{3}{*}{ Year of diagnosis } & & & & & 9.597 & 0.002 \\
\hline & 2004-2008 & 6656 & 672 & 5984 & & \\
\hline & 2009-2012 & 3844 & 463 & 3381 & & \\
\hline \multirow[t]{3}{*}{ Age } & & & & & 60.255 & 0.000 \\
\hline & $<60$ & 9236 & 918 & 8318 & & \\
\hline & $\geq 60$ & 1264 & 217 & 1047 & & \\
\hline \multirow[t]{4}{*}{ Race } & & & & & 56.815 & 0.000 \\
\hline & White & 8389 & 829 & 7560 & & \\
\hline & Black & 956 & 170 & 786 & & \\
\hline & Others & 1155 & 136 & 1019 & & \\
\hline \multirow[t]{4}{*}{ Grade } & & & & & 20.861 & 0.000 \\
\hline & $\mathrm{I} / \mathrm{II}$ & 4955 & 466 & 4489 & & \\
\hline & III/IV & 3394 & 395 & 2999 & & \\
\hline & Unknown & 2151 & 274 & 1877 & & \\
\hline \multirow[t]{5}{*}{ Primary Site } & & & & & 0.649 & 0.885 \\
\hline & Endocervix & 2377 & 256 & 2121 & & \\
\hline & Exocervix & 338 & 33 & 305 & & \\
\hline & Overlapping lesion & 343 & 40 & 303 & & \\
\hline & Cervix uteri & 7442 & 806 & 6636 & & \\
\hline \multirow[t]{4}{*}{ Histologic type } & & & & & 9.019 & 0.011 \\
\hline & $\begin{array}{l}\text { Squamous cell } \\
\text { carcinoma }\end{array}$ & 7377 & 841 & 6536 & & \\
\hline & Adenocarcinoma & 2901 & 274 & 2627 & & \\
\hline & $\begin{array}{l}\text { Mucinous } \\
\text { adenocarcinoma }\end{array}$ & 222 & 20 & 202 & & \\
\hline \multirow[t]{6}{*}{ FIGO stage } & & & & & 256.214 & 0.000 \\
\hline & I & 7343 & 644 & 6699 & & \\
\hline & II & 1003 & 184 & 819 & & \\
\hline & III & 261 & 89 & 172 & & \\
\hline & IV & 32 & 11 & 21 & & \\
\hline & Unknown & 1861 & 207 & 1654 & & \\
\hline \multirow[t]{3}{*}{ Radiation } & & & & & 168.765 & 0.000 \\
\hline & No radiation & 7299 & 590 & 6639 & & \\
\hline & $\begin{array}{l}\text { Radiation after } \\
\text { surgery }\end{array}$ & 3271 & 545 & 2726 & & \\
\hline
\end{tabular}

FIGO stage. Apparently, NLN count is a good supplement for evaluation prognosis of FIGO stage.

Until now, there is no conclusion of mechanism of NLNs effecting on the prognosis of cervical cancer. Heeren et al. identified that an increased number of regulatory $\mathrm{T}$ cells (Treg) and the decreased CD8+ $\mathrm{T}$ cell/Treg ratio were found at both positive and negative lymph nodes in the regional lymph node area of cervical cancer patients, reflecting an immune suppressive microenvironment that promotes metastatic spread [23]. On the other hand, lymphatic micrometastasis is important to the prognosis of cervical cancer. Since it was difficult to find lymphatic micrometastasis during operation, we have to retrieve more NLNs to reduce the residual micrometastases and improve the prognosis of cervical cancer, which was consistent to our results.

Extent of lymphadenectomy is a matter of debate for cervical cancer treatment. Various studies have examined whether the number of retrieved lymph nodes would affect survival of cervical cancer patients. Lim et al. 
Table 2: Univariate analysis of the influence of different NLN count on CSS in patients with cervical cancer

\begin{tabular}{|c|c|c|c|c|c|c|c|c|c|}
\hline NLN & No. & 5-year CCS & $\chi^{2}$ & $P$ value & NLN & No. & 5-year CCS & $\chi^{2}$ & $P$ value \\
\hline$\leq 0$ & 49 & $40.8 \%$ & \multirow{2}{*}{160.499} & \multirow{2}{*}{0.000} & $\leq 12$ & 3143 & $85.1 \%$ & \multirow{2}{*}{80.909} & \multirow{2}{*}{0.000} \\
\hline$>0$ & 10451 & $89.6 \%$ & & & $>12$ & 7357 & $91.2 \%$ & & \\
\hline$\leq 1$ & 173 & $60.0 \%$ & \multirow{2}{*}{173.818} & \multirow{2}{*}{0.000} & $\leq 13$ & 3545 & $86.1 \%$ & \multirow{2}{*}{57.158} & \multirow{2}{*}{0.000} \\
\hline$>1$ & 10327 & $89.8 \%$ & & & $>13$ & 6955 & $91.0 \%$ & & \\
\hline$\leq 2$ & 349 & $68.4 \%$ & \multirow{2}{*}{169.186} & \multirow{2}{*}{0.000} & $\leq 14$ & 3937 & $86.5 \%$ & \multirow{2}{*}{55.397} & \multirow{2}{*}{0.000} \\
\hline$>2$ & 10151 & $90.1 \%$ & & & $>14$ & 6563 & $91.1 \%$ & & \\
\hline$\leq 3$ & 482 & $70.4 \%$ & \multirow{2}{*}{214.406} & \multirow{2}{*}{0.000} & $\leq 15$ & 4323 & $86.8 \%$ & \multirow{2}{*}{51.082} & \multirow{2}{*}{0.000} \\
\hline$>3$ & 10018 & $90.3 \%$ & & & $>15$ & 6177 & $91.2 \%$ & & \\
\hline$\leq 4$ & 670 & $73.4 \%$ & \multirow{2}{*}{220.302} & \multirow{2}{*}{0.000} & $\leq 16$ & 4718 & $87.0 \%$ & \multirow{2}{*}{50.894} & \multirow{2}{*}{0.000} \\
\hline$>4$ & 9830 & $90.4 \%$ & & & $>16$ & 5782 & $91.3 \%$ & & \\
\hline$\leq 5$ & 867 & $75.4 \%$ & \multirow{2}{*}{213.032} & \multirow{2}{*}{0.000} & $\leq 17$ & 5093 & $87.3 \%$ & \multirow{2}{*}{40.925} & \multirow{2}{*}{0.000} \\
\hline$>5$ & 9633 & $90.6 \%$ & & & $>17$ & 5407 & $91.3 \%$ & & \\
\hline$\leq 6$ & 1135 & $78.3 \%$ & \multirow{2}{*}{182.842} & \multirow{2}{*}{0.000} & $\leq 18$ & 5444 & $87.5 \%$ & \multirow{2}{*}{44.011} & \multirow{2}{*}{0.000} \\
\hline$>6$ & 9365 & $90.7 \%$ & & & $>18$ & 5056 & $91.3 \%$ & & \\
\hline$\leq 7$ & 1404 & $80.2 \%$ & \multirow{2}{*}{149.141} & \multirow{2}{*}{0.000} & $\leq 19$ & 5870 & $87.9 \%$ & \multirow{2}{*}{34.635} & \multirow{2}{*}{0.000} \\
\hline$>7$ & 9096 & $90.8 \%$ & & & $>19$ & 4630 & $91.2 \%$ & & \\
\hline$\leq 8$ & 1709 & $81.7 \%$ & 123485 & 0000 & $\leq 20$ & 6202 & $88.0 \%$ & 22770 & 次 \\
\hline$>8$ & 8791 & $90.8 \%$ & 123.485 & 0.000 & $>20$ & 4298 & $91.3 \%$ & 32.170 & 0.000 \\
\hline$\leq 9$ & 2059 & $83.2 \%$ & 100117 & ( & $\leq 21$ & 6536 & $88.1 \%$ & 20075 & ( \\
\hline$>9$ & 8441 & $90.9 \%$ & 100.11 & & $>21$ & 3964 & $91.4 \%$ & 20.020 & \\
\hline$\leq 10$ & 2396 & $84.1 \%$ & 00805 & (1) & $\leq 22$ & 6872 & $88.3 \%$ & 52 & ( \\
\hline$>10$ & 8104 & $90.9 \%$ & 90.093 & 0.000 & $>22$ & 3628 & $91.3 \%$ & 24.252 & 0.000 \\
\hline$\leq 11$ & 2761 & $84.4 \%$ & 01026 & 0000 & $\leq 23$ & 7141 & $88.4 \%$ & 262 & 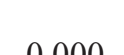 \\
\hline$>11$ & 7739 & $91.1 \%$ & טעם & 0.000 & $>23$ & 3359 & $91.4 \%$ & 22.502 & 0.000 \\
\hline
\end{tabular}

[24] found that the number of retrieved lymph nodes was an independent prognostic factor for cervical cancer treatment in bulky cervical cancer group. In this group, more than 40 lymph nodes had a significant positive effect on disease-free survival and overall survival using multivariate analysis. However, the number of retrieved lymph nodes was not an independent prognostic factor in the non-bulky cervical cancer group. Mao et al. [25] showed that if a standardized lymphadenectomy was performed, the number of lymph nodes removed was not an independent prognostic factor for patients with nodenegative early cervical cancer. Zhou et al. [18] found that the number of positive lymph nodes had prognostic value in cervical squamous cell carcinoma and adenosquamous carcinoma, but not in cervical adenocarcinoma. Also, the number of positive lymph nodes is an independent risk factor for CSS of cervical cancer patients. In addition, Garg et al. [26] and Srisomboon et al. [27] explored the impact of different treatments on the prognosis of early cervical cancer. But no relationship between NLN count and prognosis was found in the setting of cervical cancer previously. Lymphatic micrometastasis plays an important role in the prognosis of cervical cancer. Since it was difficult to find lymphatic micrometastasis during operation, more NLNs have to be retrieved to reduce the residual micrometastases to improve the prognosis of cervical cancer. Thus, NLN count may perform better than total lymph node count or positive lymph node for prediction of survival.

The relationship between lymph node count and outcome was controversial in the treatment of cervical cancer. Because the majority of patients with early stage cervical cancer do not have lymph node metastases. The extensive lymphadenectomy was unnecessary and could cause complications such as lymphedema [25]. Pieterse et al. [28] concluded that more lymph nodes retrieved is 
related to longer survivals of patients with positive nodes. Similar results were found in the studies of Shah et al. [19] and Lim et al. [24], which concluded that early-stage cervical cancer patients who underwent a more extensive lymphadenectomy had longer survivals. In contrast, Ditto et al. [17] revealed that the number of lymph nodes had no effect on survival. The node-positive patients with cervical cancer are heterogeneous and the prognosis of these patients cannot be stratified by the definite nodestage. Thus, the concept of NLN count may serve as a prognostic indicator in various cancers.

This study has several limitations. Firstly, different operative approaches, doctors and even pathologist would affect lymph nodes harvest, which cannot be adjusted in analysis. Secondly, the SEER database does not have the information of subsequent therapy including adjuvant chemotherapy, radiotherapy and targeted therapy, comorbidities and recurrence, which may also impact
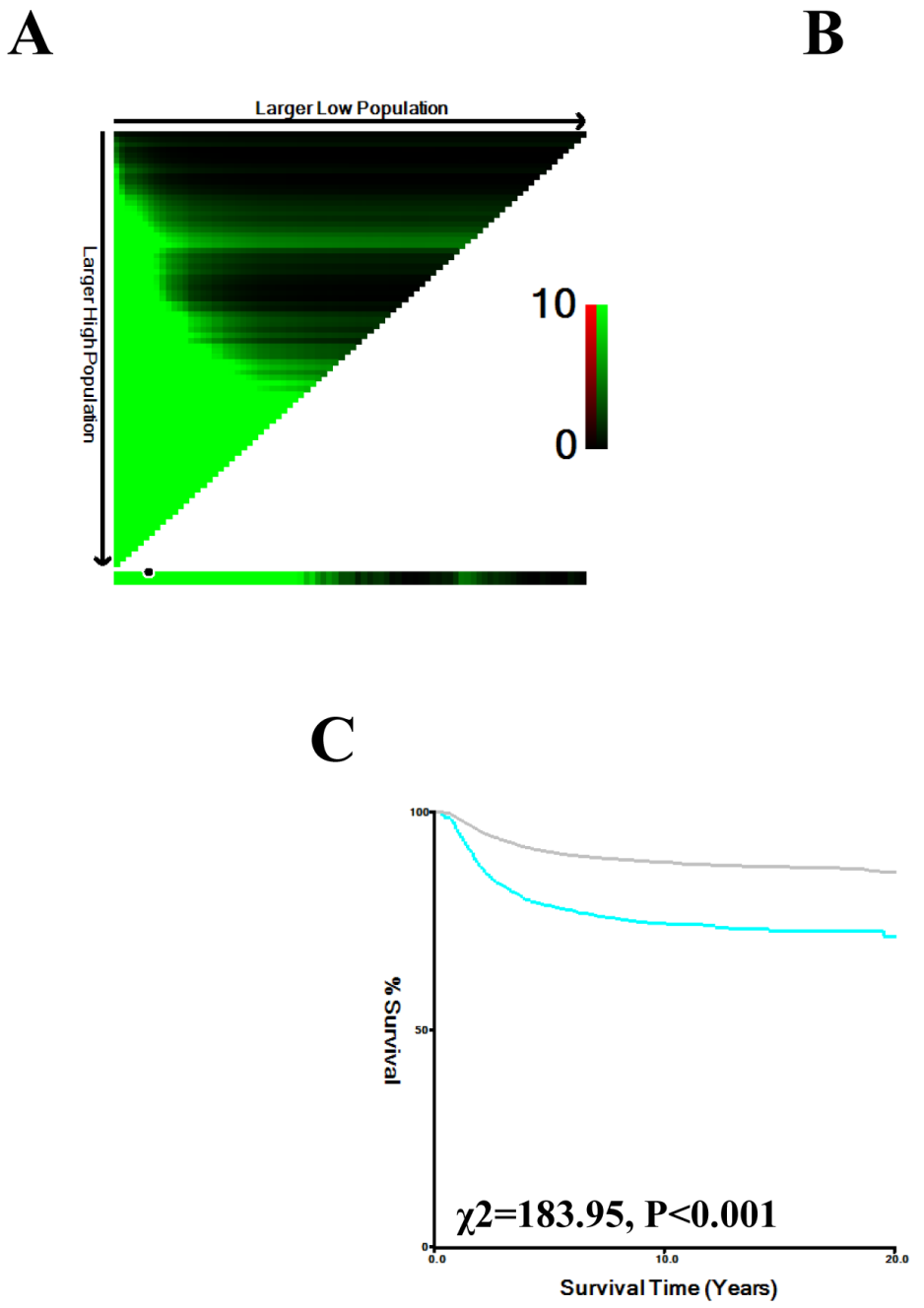

Figure 1: X-tile analysis of survival data from the SEER registry. X-tile analysis was performed using patient data, equally divided into training and validation sets, from the SEER registry. X-tile plots of the training sets are shown in the left panels, with plots of matched validation sets shown in the smaller inset. The optimal cut-point highlighted by the black circle in the left panels is shown on a histogram of the entire cohort (middle panels), and a Kaplan-Meier plot (right panels). $P$ values were determined using the cutoff point defined in the training set and applying it to the validation set. (The optimal cutoff value for NLN count is $6, \chi^{2}=183.95, P<0.001$ ). 
Table 3: Univariate and multivariate survival analysis of cervical cancer patients who received radical surgery

\begin{tabular}{|c|c|c|c|c|c|c|c|}
\hline \multirow{2}{*}{ Parameter } & \multirow{2}{*}{ Characteristic } & \multirow{2}{*}{$\begin{array}{c}\text { 3-year } \\
\text { CCS }\end{array}$} & \multirow{2}{*}{$\begin{array}{c}\text { 5-year } \\
\text { CCS }\end{array}$} & \multicolumn{2}{|c|}{ Univariate analysis } & \multicolumn{2}{|c|}{ Multivariate analysis } \\
\hline & & & & $\begin{array}{c}\text { Log rank } \\
\chi 2 \text { test }\end{array}$ & $\boldsymbol{P}$ & HR (95\%CI) & $\boldsymbol{P}$ \\
\hline \multirow[t]{3}{*}{ Year of diagnosis } & & & & 1.743 & 0.187 & NI & \\
\hline & 2004-2008 & $88.1 \%$ & $83.5 \%$ & & & & \\
\hline & 2009-2012 & $88.9 \%$ & $82.3 \%$ & & & & \\
\hline \multirow[t]{3}{*}{ Age } & & & & 77.726 & 0.000 & & 0.002 \\
\hline & $<60$ & $89.1 \%$ & $84.2 \%$ & & & Ref & \\
\hline & $\geq 60$ & $83.1 \%$ & $74.5 \%$ & & & $0.805(0.699 \sim 0.926)$ & 0.002 \\
\hline \multirow[t]{4}{*}{ Race } & & & & 12.908 & 0.002 & & 0.009 \\
\hline & White & $88.8 \%$ & $83.6 \%$ & & & Ref & \\
\hline & Black & $85.8 \%$ & $79.1 \%$ & & & $1.064(0.895 \sim 1.265)$ & 0.482 \\
\hline & Others & $87 . .8 \%$ & $82.3 \%$ & & & $1.350(1.082 \sim 1.685)$ & 0.008 \\
\hline \multirow[t]{4}{*}{ Grade } & & & & 156.785 & 0.000 & & 0.000 \\
\hline & $\mathrm{I} / \mathrm{II}$ & $90.6 \%$ & $85.5 \%$ & & & Ref & \\
\hline & III/IV & $83.0 \%$ & $76.6 \%$ & & & $1.242(1.037 \sim 1.488)$ & 0.019 \\
\hline & Unknown & $91.9 \%$ & $87.4 \%$ & & & 1.966 (1.645 2.349) & 0.000 \\
\hline \multirow[t]{5}{*}{ Primary Site } & & & & 24.410 & 0.000 & & 0.266 \\
\hline & Endocervix & $91.5 \%$ & $86.2 \%$ & & & Ref & \\
\hline & Exocervix & $87.9 \%$ & $84.3 \%$ & & & $0.858(0.732 \sim 1.006)$ & 0.059 \\
\hline & Overlapping lesion & $87.8 \%$ & $83.1 \%$ & & & $0.987(0.719 \sim 1.354)$ & 0.934 \\
\hline & Cervix uteri & $87.4 \%$ & $82.0 \%$ & & & $0.881(0.646 \sim 1.200)$ & 0.421 \\
\hline \multirow[t]{4}{*}{ Histologic type } & & & & 70.867 & 0.000 & & 0.000 \\
\hline & Squamous cell carcinoma & $87.0 \%$ & $81.3 \%$ & & & Ref & \\
\hline & Adenocarcinoma & $92.2 \%$ & $87.9 \%$ & & & $0.473(0.353 \sim 0.633)$ & 0.000 \\
\hline & $\begin{array}{l}\text { Mucinous } \\
\text { adenocarcinoma }\end{array}$ & $84.7 \%$ & $76.1 \%$ & & & $0.5440 .404 \sim 0.733)$ & 0.000 \\
\hline \multirow[t]{6}{*}{ FIGO stage } & & & & 934.468 & 0.000 & & 0.000 \\
\hline & I & $92.4 \%$ & $88.0 \%$ & & & Ref & \\
\hline & II & $73.7 \%$ & $64.7 \%$ & & & $0.647(0.560 \sim 0.748)$ & 0.000 \\
\hline & III & $58.2 \%$ & $48.7 \%$ & & & $1.406(1.192 \sim 1.658)$ & 0.000 \\
\hline & IV & $21.8 \%$ & $15.6 \%$ & & & 2.367 (1.908 2.937) & 0.000 \\
\hline & Unknown & $85.9 \%$ & $79.2 \%$ & & & $6.989(4.644 \sim 10.518)$ & 0.000 \\
\hline \multirow[t]{3}{*}{ Radiation } & & & & 608.573 & 0.000 & & 0.000 \\
\hline & No radiation & $92.9 \%$ & $89.0 \%$ & & & Ref & \\
\hline & Radiation after surgery & $78.4 \%$ & $69.9 \%$ & & & $0.321(0.282 \sim 0.365)$ & 0.000 \\
\hline \multirow[t]{3}{*}{ NLN } & & & & 127.645 & 0.000 & & 0.000 \\
\hline & $0 \sim 6$ & $78.3 \%$ & $71.8 \%$ & & & Ref & \\
\hline & $7 \sim$ & $89.6 \%$ & $84.4 \%$ & & & $1.571(1.370 \sim 1.801)$ & 0.000 \\
\hline
\end{tabular}

NI: not included in the multivariate survival analysis.

with a known age $(\geq 18)$. Years of diagnosis, age, race, grade, primary site, FIGO stage and CSS were extracted from the SEER database. Histological types were limited to squamous cell carcinoma (8070/3), adenocarcinoma (8140/3) and mucinous adenocarcinoma (8141/3, 8142/3). Survival time was calculated from the date of diagnosis to the date of cancer-specific death. The exclusion criterions included: age $<18$, receiving neoadjuvant therapy, no evaluation of histological type, multiple malignant neoplasms, died within 30 days or information on CSS and survival months unavailable.

\section{Statistical analysis}

The NLNs cutoff points were determined using the X-tile program (http://www.tissuearray.org/rimmlab/), 
Table 4: Univariate and multivariate analysis of NLN status on CSS of cervical cancer based on different cancer stage

\begin{tabular}{|c|c|c|c|c|c|c|c|}
\hline \multirow[t]{2}{*}{ Parameter } & \multirow[t]{2}{*}{ NLN } & \multirow[t]{2}{*}{$\begin{array}{c}\text { 3-year } \\
\text { CCS }\end{array}$} & \multirow[t]{2}{*}{$\begin{array}{c}\text { 5-year } \\
\text { CCS }\end{array}$} & \multicolumn{2}{|c|}{ Univariate analysis } & \multicolumn{2}{|c|}{ Multivariate analysis } \\
\hline & & & & Log rank $\chi^{2}$ test & $P$ & HR(95\%CI) & $P$ \\
\hline \multicolumn{8}{|l|}{ FIGO stage } \\
\hline \multirow[t]{3}{*}{ Stage I } & & & & 35.023 & 0.000 & & 0.000 \\
\hline & $0 \sim 6$ & $89.0 \%$ & $83.2 \%$ & & & Ref & \\
\hline & $7 \sim$ & $92.7 \%$ & $88 . .5 \%$ & & & 1.685 (1.338 2.122) & 0.000 \\
\hline \multirow[t]{3}{*}{ Stage II } & & & & 12.910 & 0.000 & & 0.002 \\
\hline & $0 \sim 6$ & $60.3 \%$ & $54.9 \%$ & & & Ref & \\
\hline & $7 \sim$ & $76.7 \%$ & $66.9 \%$ & & & $1.512(1.163 \sim 1.965)$ & 0.002 \\
\hline \multirow[t]{3}{*}{ Stage III + IV } & & & & 9.732 & 0.002 & & 0.005 \\
\hline & $0 \sim 6$ & $46.0 \%$ & $33.0 \%$ & & & Ref & \\
\hline & $7 \sim$ & $58.5 \%$ & $51.3 \%$ & & & $1.608(1.154 \sim 2.242)$ & 0.005 \\
\hline \multirow{3}{*}{$\begin{array}{l}\text { Unknown } \\
\text { stage }\end{array}$} & & & & 16.654 & 0.000 & & 0.024 \\
\hline & $0 \sim 6$ & $76.8 \%$ & $70.0 \%$ & & & Ref & \\
\hline & $7 \sim$ & $87.1 \%$ & $80.4 \%$ & & & $1.438(1.050 \sim 1.971)$ & 0.024 \\
\hline
\end{tabular}

$P$-values refer to comparisons between two groups and were adjusted for age, race, grade, histologic type, FIGO stage and radiation after surgery as covariates.

A

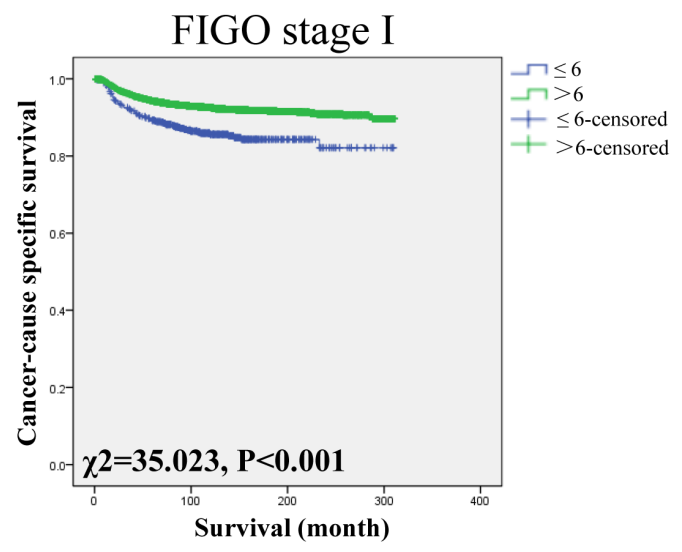

C

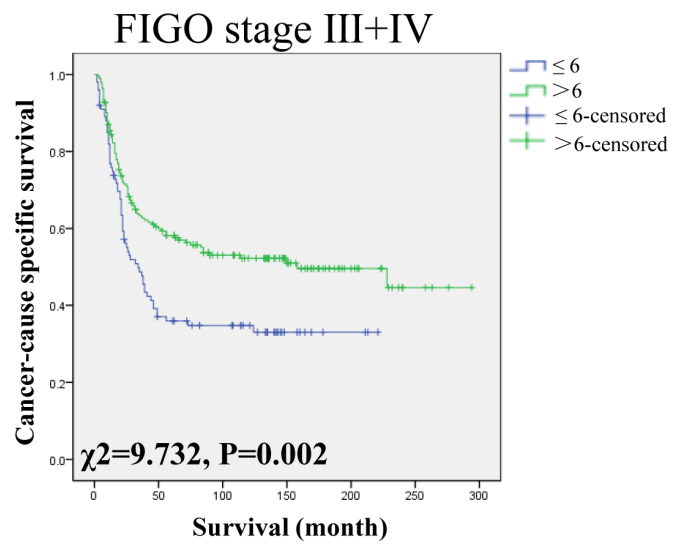

B

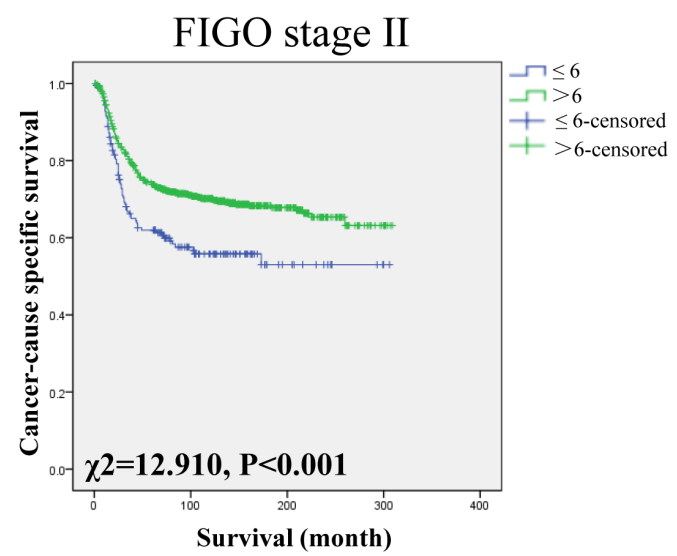

D

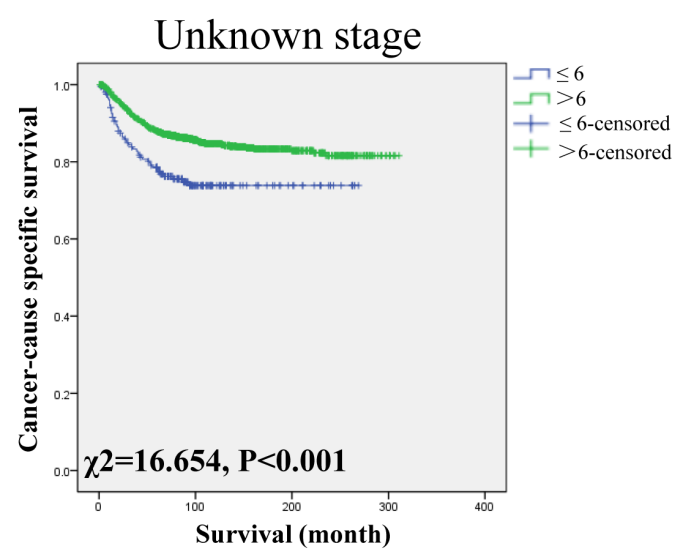

Figure 2: Log-rank tests of CSS comparing patients with NLNs $\left(\leq 6\right.$ VS $>6$ ) for $(\mathbf{A})$ FIGO stage I: $\chi^{2}=35.023, P<0.001$; (B) FIGO stage II: $\chi^{2}=12.910, P<0.001$; and (C) FIGO stage III + IV: $\chi^{2}=9.732, P=0.002$ and (D) Unknown stage: $\chi^{2}=16.654, P<0.001$. 
which identified the cutoff value with the minimum $P$ values from log-rank $\chi^{2}$ statistics for the categorical NLNs in terms of CSS.

The X-tile plot illustrates the presence of substantial tumor subpopulations and shows the robustness of the relationship between a biomarker and outcome by construction of a two dimensional projection of every possible subpopulation [29]. In our data, the variables, negative lymph node count and cancer specific survival were used. X-tile plots provide a single, global assessment of every possible way of dividing a population into low/ high or low/medium/high level marker expressions. $\mathrm{X}$-tile data are presented in a right grid where each point represents a different cut-point. The intensity of the color of each cutoff point represents the strength of the association. The X-tile software allows the user to move a cursor across the grid and provides an "on-thefly" histogram of the resulting population subsets along with an associated Kaplan-Meier curve [30]. Baseline characteristics were compared using the $\chi^{2}$ test for nominal variables. Survival curves were generated using Kaplan-Meier analyses, and the differences between the curves were analyzed by log-rank test. Cox regression models were built for analysis of risk factors for survival outcomes. Statistical analyses were performed using the statistical software package SPSS for Windows, version 19.0 (SPSS Inc., Chicago, IL). All $P$ values were twosided. $P<0.05$ was considered statistically significant.

\section{Author contributions}

$\mathrm{XL}$ and $\mathrm{ZH}$ conceived and designed the study, HW and XL performed the analyses, HL, HY and RG provided assistance in writing the manuscript and support in interpreting results. All authors discussed the results and implications of the analysis and commented on the manuscript at all stages.

\section{ACKNOWLEDGMENTS AND FUNDING}

This work was supported by grant from National Youth Science Foundation (81402002). The authors acknowledged the efforts of the SEER Program tumor registries in the creation of the SEER database. The interpretation and reporting of these data were the sole responsibility of the authors.

\section{CONFLICTS OF INTEREST} interests.

The authors declare that they have no competing

\section{REFERENCES}

1. Torre LA, Sauer AM, Chen MS Jr, Kagawa-Singer M, Jemal A, Siegel RL. Cancer statistics for Asian Americans,
Native Hawaiians, and Pacific Islanders, 2016: Converging incidence in males and females. CA Cancer J Clin. 2016; 66:182-202. https://doi.org/10.3322/caac.21335.

2. Yamagami W, Nagase S, Takahashi F, Ino K, Hachisuga T, Aoki D, Katabuchi H. Clinical statistics of gynecologic cancers in Japan. J Gynecol Oncol. 2017; 28:e32. https:// doi.org/10.3802/jgo.2017.28.e32.

3. Whitlock EP, Vesco KK, Eder M, Lin JS, Senger CA, Burda BU. Liquid-based cytology and human papillomavirus testing to screen for cervical cancer: a systematic review for the U.S. Preventive Services Task Force. Ann Intern Med. 2011; 155:687-97, W214-5. https:// doi.org/10.7326/0003-4819-155-10-201111150-00376.

4. Peirson L, Fitzpatrick-Lewis D, Ciliska D, Warren R. Screening for cervical cancer: a systematic review and meta-analysis. Syst Rev. 2013; 2:35. https://doi. org/10.1186/2046-4053-2-35.

5. Pecorelli S, Zigliani L, Odicino F. Revised FIGO staging for carcinoma of the cervix. Int J Gynaecol Obstet. 2009; 105:107-8. https://doi.org/10.1016/j.ijgo.2009.02.009.

6. Zhou J, Chen QH, Wu SG, He ZY, Sun JY, Li FY, Lin HX, You KL. Lymph node ratio may predict the benefit of postoperative radiotherapy in node-positive cervical cancer. Oncotarget. 2016; 7:29420-8. https://doi.org/10.18632/ oncotarget.8840.

7. Metindir J, Bilir G. Impact of the ratio of metastatic to examined lymph nodes on the survival of early-stage cervical cancer patients. Onkologie. 2009; 32:103-6. https://doi.org/10.1159/000197361.

8. Fleming ND, Frumovitz M, Schmeler KM, dos Reis R, Munsell MF, Eifel PJ, Soliman PT, Nick AM, Westin SN, Ramirez PT. Significance of lymph node ratio in defining risk category in node-positive early stage cervical cancer. Gynecol Oncol. 2015; 136:48-53. https://doi.org/10.1016/j. ygyno.2014.11.010.

9. Polterauer S, Hefler L, Seebacher V, Rahhal J, Tempfer C, Horvat R, Reinthaller A, Grimm C. The impact of lymph node density on survival of cervical cancer patients. Br J Cancer. 2010; 103:613-6. https://doi.org/10.1038/ sj.bjc. 6605801 .

10. Chen Y, Zhang L, Tian J, Fu X, Ren X, Hao Q. Significance of the absolute number and ratio of metastatic lymph nodes in predicting postoperative survival for the International Federation of Gynecology and Obstetrics stage IA2 to IIA cervical cancer. Int J Gynecol Cancer. 2013; 23:157-63. https://doi.org/10.1097/IGC.0b013e3182778bcf.

11. Chen Y, Zhang L, Tian J, Ren X, Hao Q. Combining the negative lymph nodes count with the ratio of positive and removed lymph nodes can better predict the postoperative survival in cervical cancer patients. Cancer Cell Int. 2013; 13:6. https://doi.org/10.1186/1475-2867-13-6.

12. Li X, Lu H, Xu K, Wang H, Liang X, Hu Z. Negative lymph node count is an independent prognostic factor for patients with rectal cancer who received preoperative radiotherapy. BMC Cancer. 2017; 17:227. https://doi.org/10.1186/ s12885-017-3222-8. 
13. He J, Wang H, Ma F, Feng F, Lin C, Qian H. Prognosis of lymph node-negative breast cancer: Association with clinicopathological factors and tumor associated gene expression. Oncol Lett. 2014; 8:1717-24. https://doi. org/10.3892/ol.2014.2339.

14. Zhu Z, Chen H, Yu W, Fu X, Xiang J, Li H, Zhang Y, Sun M, Wei Q, Zhao W, Zhao K. Number of negative lymph nodes is associated with survival in thoracic esophageal squamous cell carcinoma patients undergoing three-field lymphadenectomy. Ann Surg Oncol. 2014; 21:2857-63. https://doi.org/10.1245/s10434-014-3665-y.

15. Shi RL, Chen Q, Ding JB, Yang Z, Pan G, Jiang D, Liu W. Increased number of negative lymph nodes is associated with improved survival outcome in node positive gastric cancer following radical gastrectomy. Oncotarget. 2016; 7:35084-91. https://doi.org/10.18632/oncotarget.9041.

16. Liu Y, Zhao LJ, Li MZ, Li MX, Wang JL, Wei LH. The Number of Positive Pelvic Lymph Nodes and Multiple Groups of Pelvic Lymph Node Metastasis Influence Prognosis in Stage IA-IIB Cervical Squamous Cell Carcinoma. Chin Med J (Engl). 2015; 128:2084-9. https:// doi.org/10.4103/0366-6999.161372.

17. Ditto A, Martinelli F, Lo Vullo S, Reato C, Solima E, Carcangiu M, Haeusler E, Mariani L, Lorusso D, Raspagliesi F. The role of lymphadenectomy in cervical cancer patients: the significance of the number and the status of lymph nodes removed in 526 cases treated in a single institution. Ann Surg Oncol. 2013; 20:3948-54. https://doi.org/10.1245/s10434-013-3067-6.

18. Zhou J, Wu SG, Sun JY, Liao XL, Li FY, Lin HX, Yang LC, He ZY. Incorporation of the number of positive lymph nodes leads to better prognostic discrimination of nodepositive early stage cervical cancer. Oncotarget. 2017; 8:26057-65. https://doi.org/10.18632/oncotarget.15220.

19. Shah M, Lewin SN, Deutsch I, Burke WM, Sun X, Herzog TJ, Wright JD. Therapeutic role of lymphadenectomy for cervical cancer. Cancer. 2011; 117:310-7. https://doi.org/10.1002/cncr.25408.

20. Johnson PM, Porter GA, Ricciardi R, Baxter NN. Increasing negative lymph node count is independently associated with improved long-term survival in stage IIIB and IIIC colon cancer. J Clin Oncol. 2006; 24:3570-5. https://doi. org/10.1200/JCO.2006.06.8866.

21. Li Q, Zhuo C, Cai G, Li D, Liang L, Cai S. Increased number of negative lymph nodes is associated with improved cancer specific survival in pathological IIIB and IIIC rectal cancer treated with preoperative radiotherapy. Oncotarget. 2014; 5:12459-71. https://doi.org/10.18632/ oncotarget. 2560 .
22. Deng J, Liang H, Wang D, Sun D, Ding X, Pan Y, Liu X. Enhancement the prediction of postoperative survival in gastric cancer by combining the negative lymph node count with ratio between positive and examined lymph nodes. Ann Surg Oncol. 2010; 17:1043-51. https://doi. org/10.1245/s10434-009-0863-0.

23. Heeren AM, de Boer E, Bleeker MC, Musters RJ, Buist MR, Kenter GG, de Gruijl TD, Jordanova ES. Nodal metastasis in cervical cancer occurs in clearly delineated fields of immune suppression in the pelvic lymph catchment area. Oncotarget. 2015; 6:32484-93. https://doi.org/10.18632/ oncotarget.5398.

24. Lim S, Cho K, Lee S, Lee K, Shin J, Chung D, Park C. Effect of number of retrieved lymph nodes on prognosis in FIGO stage IB-IIA cervical cancer patients treated with primary radical surgery. J Obstet Gynaecol Res. 2017; 43:211-9. https://doi.org/10.1111/jog.13171.

25. Mao S, Dong J, Li S, Wang Y, Wu P. Prognostic significance of number of nodes removed in patients with node-negative early cervical cancer. J Obstet Gynaecol Res. 2016; 42:1317-25. https://doi.org/10.1111/jog.13058.

26. Garg G, Shah JP, Toy EP, Field JB, Bryant CS, Liu JR, Morris RT. Intra-operative detection of nodal metastasis in early stage cervical cancer: a survey of the practice patterns of SGO members. Gynecol Oncol. 2011; 121:143-7. https:// doi.org/10.1016/j.ygyno.2010.12.337.

27. Srisomboon J, Kietpeerakool C, Suprasert P, Manopanya M, Siriaree S, Charoenkwan K, Cheewakriangkrai C, SaeTeng C. Survival and prognostic factors comparing stage IB 1 versus stage IB 2 cervical cancer treated with primary radical hysterectomy. Asian Pac J Cancer Prev. 2011; 12:1753-6.

28. Pieterse QD, Kenter GG, Gaarenstroom KN, Peters AA, Willems SM, Fleuren GJ, Trimbos JB. The number of pelvic lymph nodes in the quality control and prognosis of radical hysterectomy for the treatment of cervical cancer. Eur $\mathbf{J}$ Surg Oncol. 2007; 33:216-21. https://doi.org/10.1016/j. ejso.2006.09.037.

29. Camp RL, Dolled-Filhart M, Rimm DL. X-tile: a new bio-informatics tool for biomarker assessment and outcome-based cut-point optimization. Clin Cancer Res. 2004; 10:7252-9. https://doi.org/10.1158/1078-0432. CCR-04-0713.

30. Wang YL, Li DS, Wang Y, Wang ZY, Ji QH. Lymph node ratio for postoperative staging of laryngeal squamous cell carcinoma with lymph node metastasis. PLoS One. 2014; 9:e87037. https://doi.org/10.1371/journal.pone.0087037. 